\title{
A BUSINESS MODEL FOR CULTURAL SERVICES: JOINT DESIGN AND PRODUCTION OF A CUSTOMER EXPERIENCE
}

\author{
Beatriz Muñoz-Seca
}




\title{
A BUSINESS MODEL FOR CULTURAL SERVICES: JOINT DESIGN AND PRODUCTION OF A CUSTOMER EXPERIENCE
}

\author{
Beatriz Muñoz-Seca ${ }^{1}$
}

\begin{abstract}
Culture has grown remote from the general public and needs to be recaptured. Social and economic recognition of the role culture plays is essential and can only come about if culture is for all, not just for the few.
\end{abstract}

New audiences, new demands, new business models: the sector needs to open and reinvent itself.

In this article we consider culture as a service that needs to be designed from the point of view of a customer experience.

A customer experience looks beyond the specific cultural performance to design an interrelated set of events that will give each customer full exposure to activities and situations that enhance his or her understanding of the artistic endeavor.

An integrated service experience must come from a portfolio of institutions, or companies, working together to design and deliver a complete customer experience. A cultural service is a co-production among a group of institutions and the customer, resulting in a customer experience. This conveys a new business model for culture. This notion of a "cultural service experience" makes culture accessible to new audiences by providing new facets that plunge the audience into the creative process.

To attain this goal, cultural institutions and enterprises must take two steps.

First, they must design their own separate customer experience. Second, they must join forces with one another to jointly design and produce cultural services.

Both steps require a deeper understanding of the institutions' operational structure and a frame of reference to assist them in the separate and joint design of the customer experience.

This article presents the Service Activity Sequence, or SAS as an operational framework that will serve this purpose.

The SAS describes the activities involved in designing a customer experience and analyzes the operational structure required to bring several complementary players together to produce an integrated customer experience

Keywords: culture, business model, service design, experience design, service operations, customer experience.

${ }^{1}$ Professor, Production, Technology and Operations Management, IESE 


\section{A BUSINESS MODEL FOR CULTURAL SERVICES: JOINT DESIGN AND PRODUCTION OF A CUSTOMER EXPERIENCE}

\section{Introduction}

Culture has many facets: it can be a source of personal development, a tool of social cohesion, and a driver of economic development. In this article we present an approach that will help manage the contribution of culture to economic development. For culture to be able to enhance development, it must become an intrinsic part of everyday life. The concept of culture as an "amusement" for an elite or as a treasure to be jealously guarded by self-serving custodians is obsolete. In the current economic scenario the divorce of culture from common people calls the very existence of culture into question. The world of culture needs to recapture its essence and go back to its roots as an expression of the human soul. To do that, culture needs to offer something that appeals to all segments of society, which it can only do by transforming its offer. Giving culture back to common people will create a market that is capable of enhancing economic development. This objective can only be achieved though the creation of new business models that will sustain the development of cultural entities.

In this article we consider culture as a service that needs to be designed from the point of view of a customer experience. A customer experience approach looks beyond the specific cultural performance to design an interrelated set of events that will give each customer full exposure to activities and situations that enhance his or her understanding of the artistic endeavor. The notion of a "cultural service experience" makes culture accessible to new audiences by providing new facets that plunge the audience into the creative process. Thus, a painting becomes much more than a painting: it becomes an understanding of the historical moment in which the picture was painted, the biography of the artist, the environment that produced the artwork, along with complementary activities such as gastronomy. All this becomes part of the experience.

To attain this goal, cultural institutions and enterprises must take two steps. First, they must design their own separate customer experience. Second, they must join forces with one another to jointly design and produce cultural services for an integrated customer experience. These steps require a deeper understanding of the institutions' operational structure and a frame of reference to assist them in the separate and joint design of the customer experience. This article 
presents the Service Activity Sequence, or SAS (Muñoz-Seca, 2011), as an operational framework that will serve this purpose. The SAS describes the activities involved in designing a customer experience and analyzes the operational structure required to bring several complementary players together to produce an integrated customer experience.

\section{A business model: Culture as a service}

The world of culture is in upheaval. Whatever its sources of funding ${ }^{1}$, it faces a tremendous scarcity of resources. All across Europe cultural institutions are suffering as a result of huge cuts in government expenditure ${ }^{2}$ (France and Germany are the only countries in the EU that have increased government spending on culture, France by $2.7 \%$ and Germany by $2.4 \%$ ). Europe is starting to look to the US sponsorship model for new ideas, yet the United States model itself seems to be in need of readjustment. Orchestras such as the renowned Philadelphia Orchestra $^{3}$ are facing tremendous funding difficulties. The main topics of discussion in the cultural sector in the United States are the creation of new business models and the dichotomy of supply versus demand. In Latin America there is a need to make culture a part of people's daily lives in order to foster social cohesion and personal development. The common theme at the Fourth Congress of Latin Culture (IV Congreso Iberoamericano de Cultura), held in September 2011 in Mar del Plata, Argentina, was the need to give culture a critical role in the development of society, rather than the ornamental function it seems to have acquired in some parts of the world. Numerous efforts to achieve this are currently under way in Latin America, including the work done by $\mathrm{SESC}^{4}$ in Brazil and the renowned "El sistema" youth orchestra program $^{5}$ in Venezuela.

In this article we define culture as a "service world". To clarify the meaning of a cultural service, let us start by defining a service as "pay for performance" [Spohrer, J. and P. Maglio, 2008]. Every discipline in the cultural sector (visual, performing, audiovisual, graphic or applied arts) delivers a "performance" in the form of a painting, play, musical score or book. If we confine ourselves to this definition, a cultural service is merely the performance. We need to look further, however. The output of culture is wider than that. It has three dimensions: an educational dimension, an aesthetic dimension, and the search for beauty through the development of curiosity. Cultural services deliver knowledge and so educate. They generate a sensitivity or awareness that develops a person's aesthetic capability and ability to detect dissonant elements ${ }^{6}$. Last but not least, by opening new perspectives and prompting a search for beauty in any form, they enhance curiosity.

\footnotetext{
${ }^{1}$ In continental Europe, Canada and Australia public funding predominates, while in the United States, the United Kingdom and Japan non-profit cultural organizations receive substantial contributions from private sources.

${ }^{2}$ United Kingdom 30\%, Ireland 12\%, Portugal 9\%, Netherlands 20\%, and Spain 12.3\% (source: Public Funding of Culture 2011, Arts and Business, United Kingdom 2011.

${ }^{3}$ The Philadelphia Orchestra, founded in 1900, is one of the "Big Five" American orchestras.

${ }^{4}$ SESC (Serviço Social do Comércio), an institution created with contributions from small and medium-sized enterprises, promotes community development through education and culture. The funds come from compulsory contributions - 1.5 per cent of the payroll - from trade and services businesses.

${ }^{5}$ El Sistema is a system of youth orchestras in Venezuela designed to save the lives of under-served children through intensive and fun participation in music. Founded in 1975 by Jose Antonio Abreu, el Sistema has become a paradigm for social action through quality music-making.

${ }^{6}$ I always say to be able to value a smooth working production line you need to have an aesthetic sensibility.
} 
So we need a different definition of service. Let us take the following: "a service is a timeperishable, intangible experience performed for a client who is acting in the role of co-producer to transform the state of the client" [Spohrer, J. and P. Maglio, 2008]. The key element in this definition is the fact that the customer is transformed through the service. Service is dynamic. Repeated experience of culture transforms its customers by causing them to grow in the educational, aesthetic and curiosity dimensions. This transformation is closely linked to the idea that the customer experience is the core of a service, and that service co-creation ${ }^{7}$ [Prahalad and Ramaswamy, 2004] is a critical aspect. In a service experience, the customer co-constructs his experience through joint problem definition and problem solving.

These ideas are a far cry from culture as practiced today. Research [Hume at al., 2005] shows that cultural managers concentrate their efforts on performance as the means of delivering artistic value and content, often minimizing the importance of service. In the performing arts there is little attempt to design a service around the customer experience. Service design ${ }^{8}$ itself is rare in cultural organizations [Stuart and Tax, 2004]. According to research [Hume at al., 2005, 2006, 2007, 2010], most companies working in the field of service design in the performing arts specialize in the design of infrastructure and other technical means of delivering a good performance, such as lighting, acoustics, or stage design. Managers perceive technical delivery as the main driver of customer satisfaction and place more emphasis on it than on the delivery of augmented features. Customers, in contrast, divide the offering into two distinct phases: the cultural offering (core service and technical elements of the show) and the service offering (entire experience). Emotional and experiential aspects have been found to be the key drivers of repeat consumption in the performing arts [Hume at al., 2010]. Customers evaluate the offering as a whole, taking the costs and all the activities that make up the service into account in their assessment of the value of the service.

Cultural institutions need to abandon the idea that the intrinsic value of their assets is sufficient for them to subsist. Of course, if you are the Musée de l'Orangerie ${ }^{9}$ and your collection includes several of Monet's Water Lilies paintings, then you play in the top league. We all have to agree that the mise en scène of the Water Lilies murals at the Orangerie is spectacular. But the scope of the offer needs to be expanded. A full customer experience would include a deeper understanding of Monet's intentions, acquired through an exploration of the context of the paintings and the circumstances in which they were produced ${ }^{10}$. It would provide a complete journey, offering a comprehensive experience built around a portfolio of learning situations. An embryonic example of this idea can be found at the Oakland Museum of California, which aims to reinvent itself as a model institution supported by strong community engagement. The museum has ambitious goals for increasing the number of local visitors from its highly diverse neighborhood. Its education department has been working with curators, researchers, and designers to share knowledge about visitor needs and to design projects that encourage visitor participation.

\footnotetext{
${ }^{7}$ Cocreation refers to the joint creation of value by the company and the customer, allowing the customer to coconstruct the service experience to suit his context through joint problem definition and problem solving. It creates an experience environment in which consumers can have active dialogue and co-construct personalized experiences. [Prahalad and Ramaswamy, 2004].

${ }^{8}$ To further explore the service design concept see Muñoz-Seca and Arenas "An overview of service design" July 2011, IESE, Technical Note 478.

${ }^{9}$ The Musée de l'Orangerie is an art gallery of impressionist and post-impressionist paintings located on the Place de la Concorde in Paris. Though most famous for being the permanent home for eight Water Lilies murals by Claude Monet, the museum also contains works by Paul Cézanne, Henri Matisse, Amedeo Modigliani, Pablo Picasso, PierreAuguste Renoir and Alfred Sisley, among others.

${ }^{10}$ Wouldn't it be wonderful to include a trip to his Giverny gardens to develop a fuller understanding of the experience?
} 


\section{The need to change}

Why should a cultural institution embark on such a journey? For two clear reasons: because the demand for culture is changing, and because financial resources are becoming scarce. This is an explosive combination, forcing institutions to tread new paths in order to survive. It has to be acknowledged that the cultural sector's needs will never be fully met by an increase in demand. The sector depends for its survival on private or public funding. All the same, while cultural institutions cannot subsist on their own, they could increase their revenues by attracting more customers and so reduce their funding requirements.

So what are the trends in cultural audiences? Let's look at some data. In the United States the profile of the arts visitor is changing and visitor numbers are falling compared to other leisure activities. ${ }^{11}$

\section{Figure 1}

Percentage of United States adults who attended a performing arts event or other arts activity at least once in the previous 12 months (\%)

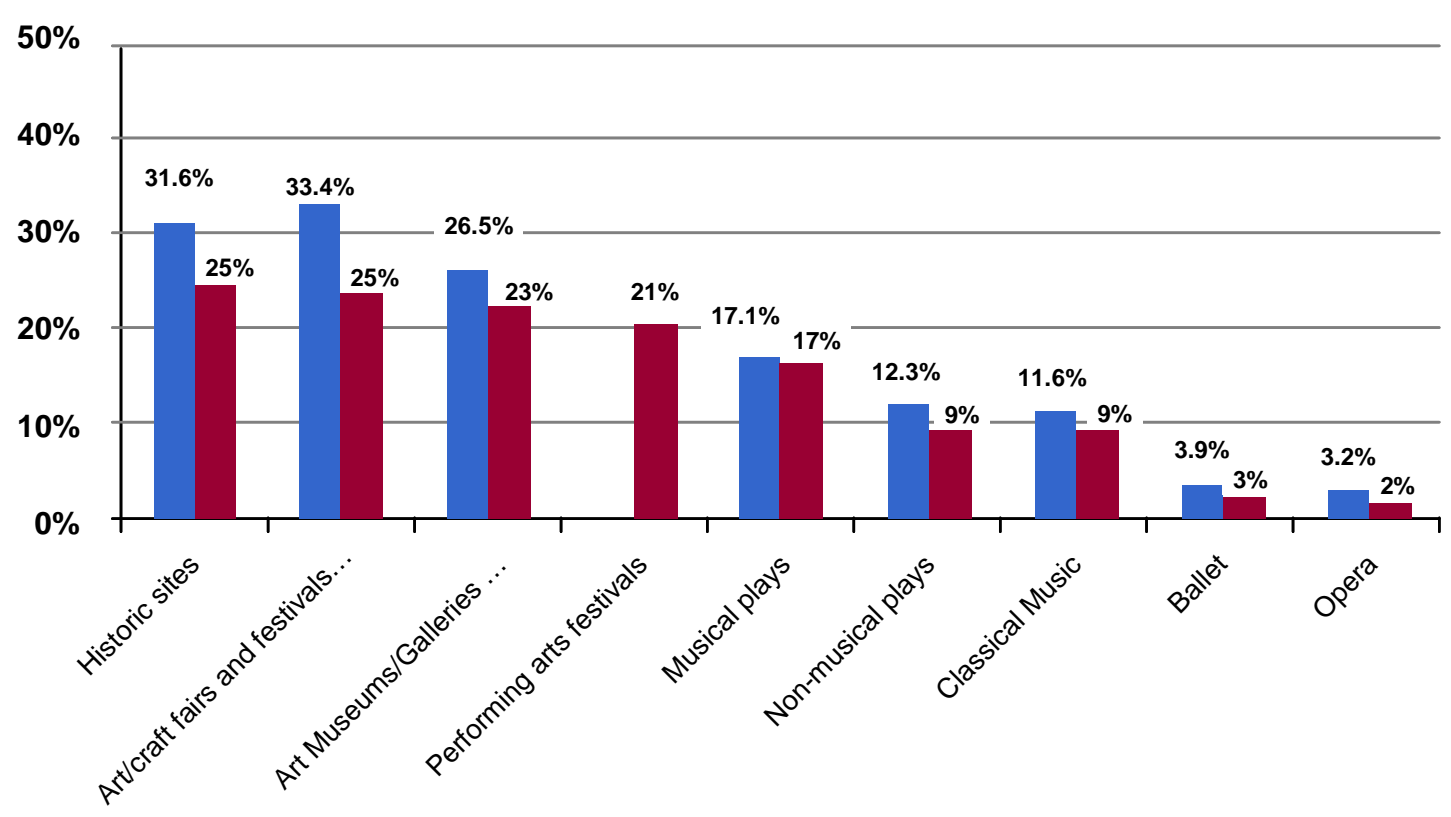

Source: 2002 and 2008 Surveys of Public Participation in the Arts.

According to the National Endowment for the Arts, in 2008 one in three adults, i.e., more than 81 million Americans, had visited a museum or attended an art performance during the twelve months preceding the survey. Attendance at cultural events in 2007-2008 was lower than in previous years and particularly low in opera $(2.1 \%)$ and ballet (7\%). The number of visitors to museums and historical monuments was also lower than in previous years (up to 21\% lower than in 2002).

\footnotetext{
${ }^{11}$ The 2008 Survey of Public Participation in the Arts (SPPA) collected arts participation data and other information from more than 18,000 adults (aged 18 and above) across the United States.
} 
In Europe, around 30 per cent of the population participates in an average of one cultural activity per year. Cinema and historical monuments are the only activities where participation exceeds 50 percent. The average age of audiences at cultural events has risen from 39 in 1982 to 45 in 2008. Thirty-nine per cent of daily Internet users use the Internet to listen to or download music, see paintings or sculptures, or publish their own artistic creations.

\section{Figure 2}

Percent of respondents who participated in cultural activities at least once in the previous 12 months, EU-27, 2002 and 2007 (\%)

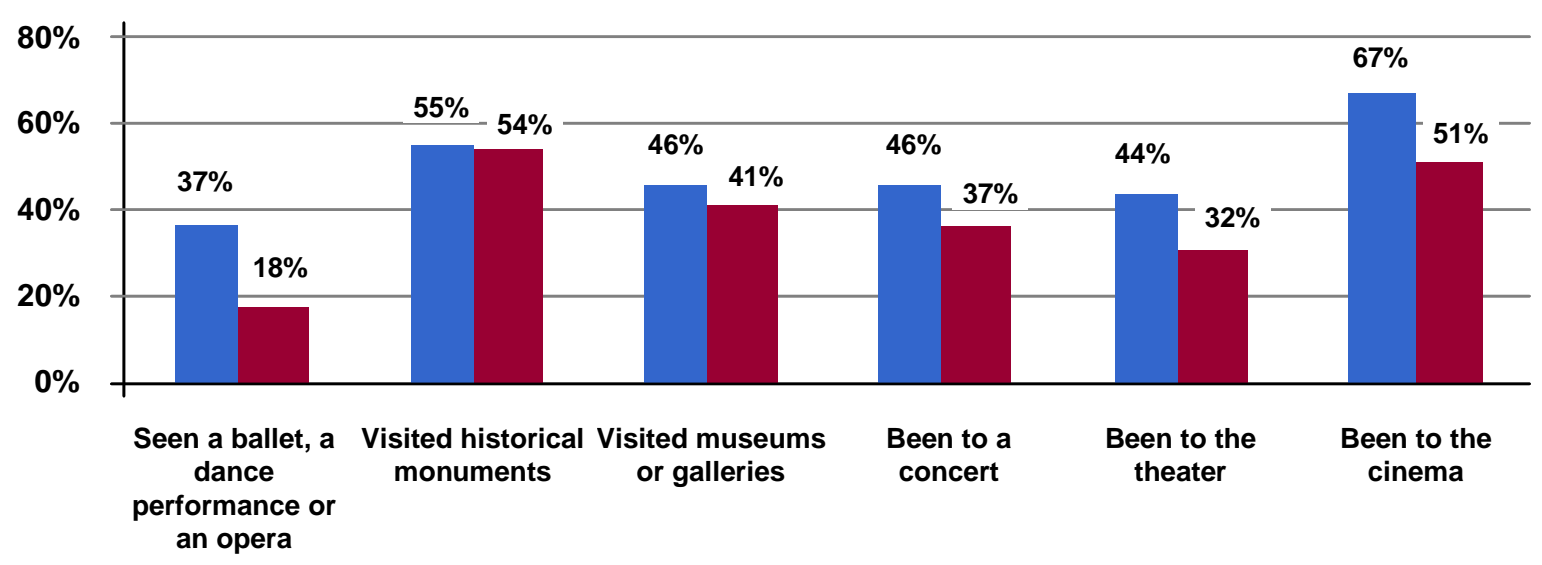

Source: Eurobarometer 67.1, 2007 (http://www.aulaintercultural.org/IMG/pdf/eurostat.pdf); and Spadaro, Rosario (2002): "Europeans' participation in cultural activities. A Eurobarometer Survey carried out at the request of the European Commission, Eurostat" (http://ec.europa.eu/culture/pdf/doc967_en.pdf).

Besides age, another very important social factor in the segmentation of the arts market is the ethnic make-up of the audience. In the United States ${ }^{12}$ in 2008 non-Hispanic white Americans made up 67 per cent of the total United States population and 80 per cent of museum visitors, while the remaining 36 per cent of the population, consisting mainly of Hispanics/Latinos and African Americans, accounted for only 9 per cent of museum visitors. In 25 years' time these latter two groups will account for almost 50 per cent of the total United States population. Similar trends can be observed in Spain, which, according to an OECD report, is the world's second largest recipient of immigrants.

This data clearly demonstrates that the current offer does not meet customer demands. A transformation is needed. According to Radbourne [2007], the new arts consumer is in search of a cultural experience which fulfills a need that has very little to do with the traditional arts marketing plan, demonstrating that audiences will be fiercely loyal if they can experience fulfillment and realization in the arts experience.

\footnotetext{
${ }^{12}$ Demographic Transformation and the Future of Museums, B. Farrell and M. Medvedeva, The AAM Press, 2010.
} 
How are cultural institutions addressing these changes? They seem to have adopted a piecemeal, trial-and-error approach. But their efforts do not seem to be aimed at achieving an integrated customer experience. Leipzig's Spinnerei, for instance, a former cotton mill, has become the epicenter of contemporary art in the city, with more than a hundred artists living and working there. The huge complex includes 14 galleries, engraving workshops, architectural studios, an arthouse cinema, and so on. The Spinnerei is also the venue for British artist Jim Whiting's Bimbotown Parties, mixing music and performance with samples of European art. Also in Leipzig, art connoisseurs can sleep in the "Paris Syndrome" Hotel, a hotel/apartment designed by the artist Jun Yang and installed in the Museum of Contemporary Art. Another example comes from the Times Square Alliance ${ }^{13}$ in NYC, featuring an outdoor exhibition of four sculptures, in partnership with the Armory Art Show. This joint initiative gave the galleries taking part in the Armory Arts Week 2011 a chance to explore New York City's public spaces and bring their artists to the attention of a wider audience.

These are examples of attempts to attract new audiences, but they do not take into account all the activities that a customer experience requires. Designing and producing a customer experience requires a frame of reference, a sort of "bookcase" in which to organize ideas and actions. We propose the Service Activity Sequence, or SAS [Muñoz-Seca, 2011], as such a framework. The SAS has been conceived with the aim of helping managers understand the dynamics of their service operations. Problem solving and the design of a customer experience are at the core of the SAS.

In the following section we will describe the SAS. We will give examples of cultural institutions that have already taken steps to develop a different approach by reinventing some of the SAS activities. This is a strong starting point. The SAS framework will help to identify other activities that will contribute to the complete customer experience.

\section{The Service Activity Sequence as an operational construct for the business model}

The SAS comprises seven activities (see Figure 3), in three groups: service design, operational infrastructure, and delivery and sustainability. Service design goes from concept development and prototyping to service engineering. Operational infrastructure deals with the configuration of the service's operational structure and the definition of service performance indicators. Delivery and sustainability addresses the requirements for the actual service delivery. It also covers service improvement requirements and extracts new features to meet customers' unmet needs. These new features are then fed back to the design chain, giving rise to the service innovation loop. Service delivery agents have a treasure of information that belongs to them, not to the company. The service innovation loop creates a path for knowledge materialization and organizational learning.

\footnotetext{
${ }^{13}$ The Times Square Alliance, founded in 1992, works to improve and promote Times Square. It promotes local businesses and encourages economic development and public improvements (www.timessquarenyc.org).

6 - IESE Business School-University of Navarra
} 


\section{Figure 3}

The SAS

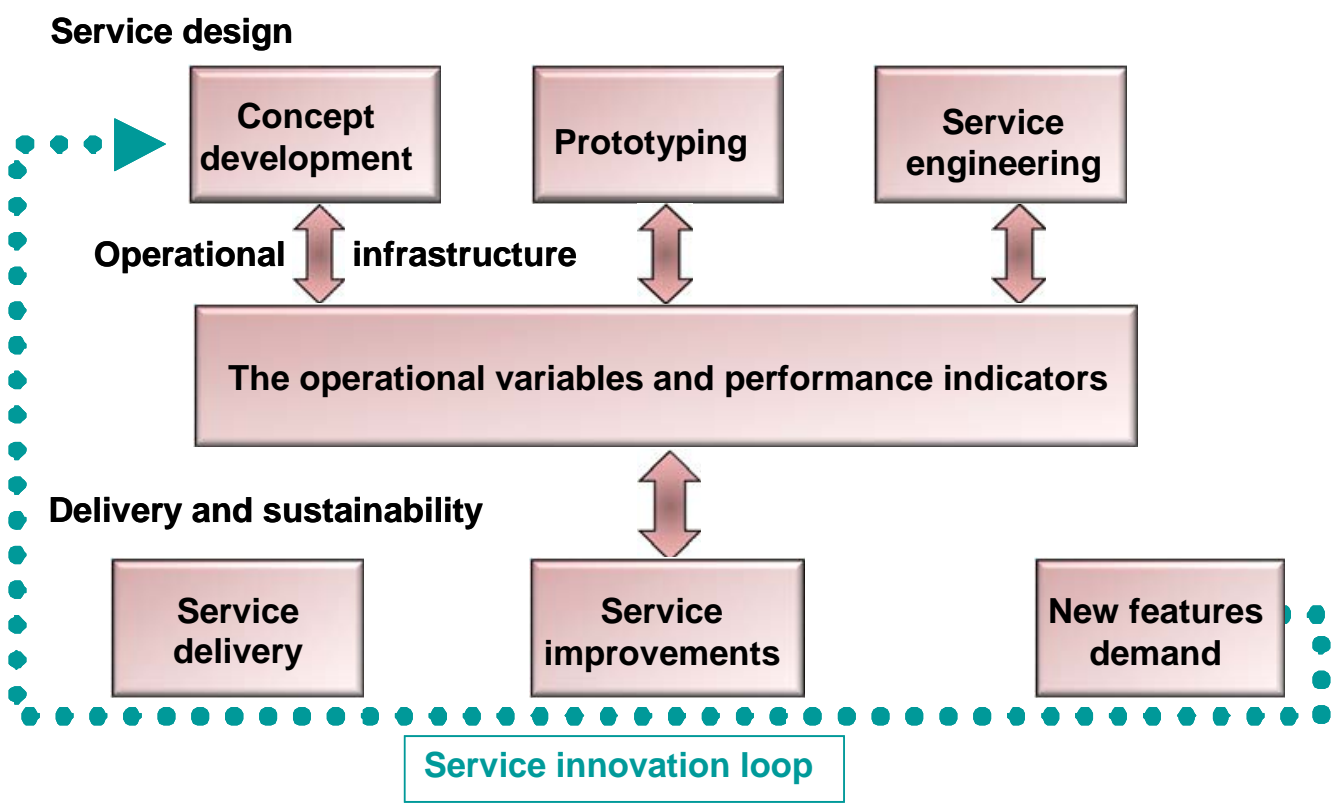

Source: Own elaboration.

The design of the customer experience starts with concept development. Experience design as a first step in service design is illustrated by the Finnish Theatre Academy's "Tourism Drama", a project in which the methods of playwriting and staging are used as a model for designing tourism experiences. Tourism professionals brainstorm ideas for the "theme" and "plot", engage in creative writing, plan the "roles", build the "stage" and "props", and so on. Ideas for the script and for the staged experience are sought in local stories, anecdotes and the social or cultural history of the place or event. Tourists are then brought to the "stage" and play an active part in the "play", co-creating their tourism experience with the help of professional facilitators or "stagers".

Concept development needs to address the essence ${ }^{14}$ of the service, i.e., the core message the service is intended to deliver. Customers experience a service through all five senses, and concept development crafts a set of activities that will create emotional connections through an engaging, compelling and consistent context (Zomerdijk and Voss, 2009, 2011). In the "Shaman's Drum" event for tourists in Lapland [Kokkinen, 2006], an audience silently carrying lanterns creates the atmosphere that the performers need. At bakery/restaurants in the Le Pain Quotidien chain, the design of the physical environment, including the façade and the rustic interior, conveys the impression of eating in a farmhouse, which is an important part of the customer experience. Virgin Atlantic's new Clubhouse at Heathrow airport is designed for different moods, from "business" to "play" to "relax", and has a variety of sensory features to support those moods, including olive trees, an outdoor space, and a water wall. Virgin Atlantic operates a mood lighting system on several of their aircraft to get passengers in the right mood

\footnotetext{
${ }^{14}$ According to Webster's dictionary, the essence of a thing is the properties or attributes by means of which that thing can be placed in its proper class or identified as being what it is.
} 
for take-off, eating, and sleeping. In a recent overview of the world's best airlines, customers chose Virgin as number one.

Prototyping helps turn ideas into services through testing, tuning, and refinement. The basic idea is to detect all the initial flaws in the service experience. Rehearsals in the performing arts are a classic example. Customer experience design requires simulations of the whole experience in order to anticipate possible problems.

The third activity, service engineering, serves two purposes. First, it sets up structures to assist in the service delivery problem-solving process. These problem-solving structures are based on an understanding of the mechanisms of any problem-solving process. Second, it defines the metaprocesses ${ }^{15}$ that determine the functional specification of the service. These meta-processes have a duality: on the one hand, they must provide the big chunks of knowledge that are required in order to materialize the service concept, providing a first definition of its components; on the other, they must set up the macro-processes required for delivering the service.

The operational infrastructure describes the activities that are required in order to bring a service to a mass market. It concentrates in the configuration of the operational variables, The setup of the operational variables ${ }^{16}$ defines the way the service must be constructed. It addresses questions such as how many people are needed, how processes will behave, what the operational rules should specify, or what type of information is needed.

These activities are complemented by the creation of service performance indicators. Much of the cultural indicator literature presents data on outputs (such as participation rates), but not on outcomes or impacts [Selwood, 2003; York, 2003]. The purpose of the indicators should not be to control, but to assess performance, in order to help choose preventive measures. Indicators will give objective measures of deviations, providing data to each agent. In the context of customer experience design, they must provide data that can be used to analyze and assess customer satisfaction with the overall experience [Muñoz-Seca and Llerena, 2011].

Delivery and sustainability starts with service delivery. The main pillar of this activity is human interaction and everything that is required in order to deliver a five-star service. Agents require clear problem-solving skills and knowledge. They are "brain workers" [Muñoz-Seca and Riverola, 2008], so the agent's knowledge profile ${ }^{17}$ will be crucial [Muñoz-Seca and Riverola, 2004]. Agents need three types of competences [Muñoz-Seca 1998, Muñoz-Seca and Riverola, 2004], namely domain competences, task competences, and inference competences. Domain and task competences relate to the knowledge needed to perform the task. Inference competences relate to problem-solving capabilities. In order to deliver a satisfactory customer experience, agents must develop these competences for dealing with situations. Tacoma Art Museum [Ferguson et al., 2006] hires employees and volunteers to fill three basic service roles, namely, Visitor Service

\footnotetext{
15 "Meta-" (from Greek: $\mu \varepsilon \tau \alpha \dot{\alpha}=$ "after", "beyond") is a prefix used to indicate that a concept is an abstraction from another concept.

${ }^{16}$ Processes, the capacity required in order to deliver the service, the structure of the flows and the configuration of the time structure, the human resources profile including problem-solving skills, the structure of information for the constant problem-solving activity, and lastly, the rules that govern the service. For a more in-depth discussion of these concepts, see Muñoz-Seca and Riverola (2004, 2008).

${ }^{17}$ The idea behind the structure of the agents' knowledge profile is simple: in order to prevent frustration when an agent is faced with an excessively challenging task, we must diagnose the knowledge gaps that may cause such frustration. Where there is a high degree of frustration, the agent will become blocked. An agent's knowledge gaps can be determined by measuring his level of knowledge in the areas that are relevant to the problem at hand.
} 
Representative, Museum and Café Personnel, and Gallery Attendant. The primary role of service personnel is to provide friendly, helpful information to customers while positively influencing customers' experience by solving their problems. The visitor service representative is expected to serve as a "concierge", informing customers where to grab lunch, what other areas to visit, and how to get to certain locations. Gallery attendants are also expected to serve as a resource, answering questions pertaining to the exhibits.

In service delivery, special attention must be paid to the impact that the existence of other customers can have on the customer experience ${ }^{18}$. Some services are individual and so are individually interfaced. In others, such as culture, the impact of other customers can be devastating. A theater on Broadway, with hordes of people queuing to get in, needs to take this into account. Technology can help. Using a CAVE $^{19}$ virtual reality environment, Juarez et al. [2010] developed a conceptual design for an exhibition by the Nationaal Historisch Museum in the Netherlands. The exhibition consisted of a virtual museum tour that reproduced events from the history of the Netherlands. Each visitor had his or her own audio and was able to interact with characters in the virtual world through a handheld device. Having separate audio and shared visuals in the virtual world meant that visitors could have both individual and group experiences. In the interactive exhibition, visitors could walk around and interact in a dynamic virtual world recreating sixteenth-century Holland, meeting people (avatars) with whom they could interact. The avatars would respond to the questions selected by the visitor. Where once audiences were seen as primarily passive [Wheeler, 2004; Boorsma 2006], now they contribute to the "co-creation of value" [Etgar, 2008].

The service improvement activity deals with the constant need to polish the customer experience. A "thousand small improvements" is the way to constantly improve services. Sometimes, small problems result in small solutions that have a tremendous impact. We should not underestimate little things: as Arthur Rubinstein, the great pianist, said, "God can be found in little details". A five-star service is based on an array of perfect little details. For a service to improve, three things are required. First, the agents must have the competences mentioned above (task, domain, and inference competences). Second, the service provider must understand that learning is its most critical asset, to be cherished above all. It must therefore value individual problem-solving and have mechanisms that guide problem-solving toward strategic goals. Third, there must be an acceptance of the possibility of failure, as learning is achieved not only through problem solving but also through generating and implementing new ideas, which can result in failure. Failure is the best way to learn and every failure is a learning opportunity for the whole company. The important thing is to erase the negative connotation. To improve means to change, and change is always a risk.

Services are living things, and the best input point for changing demands is the agent that delivers the service. The New features demand activity is focused on getting feedback from the service delivery. Its main purpose is to relay that feedback to the service design chain. This input is transformed, through concept development, into new features and service components, launching a new cycle of development of activities in the SAS. The output of this model should be a cultural offer that is more in tune with customers' unmet needs. Opera houses taking their

\footnotetext{
${ }^{18}$ This idea is taken from one of the characteristics of experience-centric services [Zomerdijk and Voss, 2009].

${ }^{19}$ A Cave Automatic Virtual Environment (CAVE) is an implementation of a virtual reality system consisting of a physical installation for image or video projection and the software that controls the installation.
} 
performances to unusual spaces such as garages are an example. According to OPERA America ${ }^{20}$ CEO Marc A. Scorca ${ }^{21}$, "Right now there's a very interesting developing trend - I can report on it in Boston, Philadelphia, Dallas - where the big opera company is reducing the number of productions and performances that it does in the big opera house in order to start doing some productions like the smaller ensembles of artists: smaller productions, in unusual spaces, of unusual repertoire. One of the things that we have found is that this new idea attracts new philanthropy." And he continues, "In the opera business you start thinking about the customer when they are in the opera house. But in the entertainment business you think about where they had dinner beforehand and what club they will go to afterward. That challenges a lot of companies, although some of them do pay attention to this, like the Opera Theater of Saint Louis, where they have a beautiful tent outside of the theater in the garden, where people have dinner beforehand and have a reception with artists afterwards. You don't go from 8 o'clock pm to 11 o'clock pm; you go from 6 pm till midnight." New features and new ways of meeting changing demands are incorporated in the offer. However, the concept development of a customer experience will need to consider the whole experience and probably add other activities.

The examples given in this section provide us with an up-to-date view of how many cultural institutions are trying to change. They are aware of the need for change. They are experimenting with new elements, without really understanding all the effects these new measures may have on their customers' experience of the service. The SAS is intended as a framework to facilitate this endeavor. A change in any one activity has an effect on all the others. And a customer experience is created by implementing all seven activities. A company that attempts to change its service without understanding the whole impact may be missing opportunities or, worse, creating a dysfunctional output.

Our business model goes a step further. For a single company or institution to create a customer experience is not sufficient. The cultural sector as a whole needs to create an integrated customer experience, basing its differentiated proposal on the joint contributions of several partners. Economic growth will come from attracting new audiences who find in culture a proposition that enhances their personal dimensions and provides alternative options for leisure.

\section{Cooperation to jointly design and produce an integrated customer experience}

The idea is simple. An integrated service experience must come from a portfolio of institutions, or companies, working together to design and deliver a complete customer experience. A cultural service is a co-production ${ }^{22}$ among a group of institutions and the customer, resulting in a customer experience. This conveys a new business model for culture.

\footnotetext{
${ }^{20}$ OPERA America provides members with tools to maximize the effectiveness of financial and human resources, expand the scope of repertoire and programs, and extend their reach to new and diverse audiences. Founded in 1970, OPERA America has an international membership that includes nearly 150 Professional Company Members, 300 Associate and Business Members, 2,000 Individual Members and over 16,000 subscribers to its electronic news service.

${ }^{21}$ Personal interview, June 2011.

${ }^{22}$ Co-production [Lengnick-Hall et al., 2000] means engaging customers as active participants in the organization's work, providing a functional [Bettencourt et al., 2002] collaborative involvement in the production of services. Customers must possess the ability to perform the behaviors that are expected of them (Groth 2005, Bowen 1986). It
} 
To attain this goal, each individual institution needs to assess its separate SAS activities and, together with other institutions, jointly design complementary actions. This approach cuts across sectors that could work together proactively. Culture thus becomes an integrating factor among sectors, playing a key role in the customer activity choice.

This idea is not totally original. Various initiatives combining culture with tourism already exist, such as the Hay Festival, and honors such as European Capital of Culture ${ }^{23}$ [Muñoz-Seca and Rodriguez, 2011]. The Hay Festival of Literature and the Arts is a very successful literary festival that has been held each year since 1988 in the Welsh village of Hay-on-Wye, attracting numerous personalities from the worlds of literature, art and politics. Since 2006 it has expanded its brand by creating Hay festivals in Bogota, Cartagena de Indias, Segovia and Granada, offering its know-how and a direct relationship with thousands of writers. In Liverpool's year as capital of culture, the city's arts venues and events received 15 million visits, $30 \%$ more than the previous year ${ }^{24}$. The numbers indicate a degree of economic success; but the lack of an integrated design may have diminished the impact.

The economic impact of festivals is a fact. In 2010 the Edinburgh International Festival ${ }^{25}$ welcomed approximately 396,000 visitors, of which 27\% spent an average of seven nights in the city. Ticket revenues topped an all-time high of 2.6 million pounds. The Avignon Theatre Festival creates about 600 jobs during the event and attracts between 100,000 and 150,000 spectators in the payment shows and an average of 30,000 in the free shows. With a budget of 10.5 million euros in 2009, more than half from government, it generated 23 million euros of economic benefits for the city. The Classical Music Festival in Salzburg generates enough income to cover 73\% of its costs and has negligible financial aid from the public sector. ${ }^{26}$ Its economic impact in Austria is around 225 million euros [Gaubinger, 2006]. The Rock in Rio pop festival held in Lisbon in 2008 had an economic impact of 87.5 million euros.

Some festivals are attempting to add to the experience. The Houston iFest music and culture festival [Rosenstein, 2009] chooses a different country or culture as its focus each year and produces a comprehensive education program for students from elementary to high school level. The cultural heart of the festival is the Living Museum, which offers a variety of iconic structures, demonstrations, and interactive hands-on exhibits, immersing festival attendees in the chosen theme. An outdoor international market offers shopping experiences involving more than 500 artists from all over the world. The international food program features cuisines from other countries, while the international music and dance program includes groups performing in diverse styles and genres.

Service design could support these efforts by providing a more comprehensive customer experience and generating new service proposals. By diagnosing all the SAS activities,

is vital that consumers understand what they are expected to do [Bowen 1986; Bowen and Waldman 1999; Lengnick-Hall et al., 2000] and are willing to contribute to various organizational activities [Escher M.C., 2007].

${ }^{23}$ The European Capital of Culture program, sponsored by the European Commission since 1985, is intended to encourage cooperation between Member States and promote mutual understanding between European citizens through culture. Each year one or two cities are designated as cultural capitals, placing them at the center of cultural activity in Europe for one year.

${ }^{24}$ Nosheen Igbal, “Liverpool culture venues welcome 15m visitors in 2008”, guardian.co.uk, Thursday, 11 December 2008.

${ }^{25}$ Launched in 1947 and a pioneer among theater festivals.

${ }^{26}$ The 2010 budget amounted to 49.5 million euros. The revenue comprised ticket sales (50\%), sponsorship (11\%), grants from the circle of friends and patrons (4\%), and other sources such as allowances for radio and TV Festival, the hiring of venues, program sales, and advertising (8\%). 
managers could find gaps and unmet demands that offered opportunities. Our proposal is to push for this type of initiative, but using systematic analysis to produce a customer experience. We present the SAS as the basis for developing this joint design and production.

A customer experience starts the moment the customer first thinks about the service. Customer experience analysis needs to look at the whole span of activities and provide answers for each one of them. Each individual provider, regardless of its size, needs to design its service experience. But not all companies can afford to have fully developed SAS activities. SMEs are "abnormal" in that they lack the required body of knowledge to tackle all customer requirements. Their size may limit their capacity to fully deal with all service requirements [Muñoz-Seca 1992]. There is no shame in this, but there is a need to understand the situation and provide alternative solutions. The answer lies not in growth but in collaboration. Companies can collaborate in individual SAS activities or concentrate on a group of activities in order to join forces and co-create a customer experience. Governments can play a crucial role in promoting this model by helping find partners to create integrated experiences and by providing sources of knowledge for companies that lack resources.

Designing and producing a joint customer experience is only one step beyond what companies are already doing today, but it could make a tremendous difference to customer appreciation of the service. A trip to Tuscany is always wonderful, but a fully developed customer experience that combines cultural assets, the performing arts, food, history, and a deeper understanding of the local way of life could be a glorious experience.

\section{Concluding remarks}

Culture should not be only for an elite. Culture is an intrinsic part of humankind and should be part of daily life. It has grown remote from the general public and needs to be recaptured. Social and economic recognition of the role culture plays is essential and can only come about if culture is for all, not just for the few.

New audiences, new demands, new business models: we need to open the whole sector and reinvent it through alternative approaches. Our proposition focuses on the customer experience and how to design and produce such an experience. The Service Activity Sequence (SAS) can accomplish that task. The SAS provides a guiding framework for developing a customer experience. It also allows for joint design of an integrated service experience among multiple institutions.

Research is needed in order to promote this idea. But cultural companies and institutions do not have much time. They need to try new approaches in order to meet their survival challenge. I hope this article will provide them with some guidance. 


\section{References}

ARC Centre of Excellence for Creative Industries and Innovation (2010), Creative Economy Report Card. April 2010.

Baker, M. and G. Sweeney (1999), Business Process Reengineering in the Hospitality Industry: Process Improvement in ALPHA Flight Services. Information Technology \& Tourism 2, pp. 45-55.

Boorsma, M. (2006), A Strategic Logic for Arts Marketing: Integrating Customer Value and Artistic Objectives, International Journal of Cultural Policy 12 (1), pp. 73-92.

Brown, T. (2008), Design thinking, Harvard Business Review.

Escher, M. C. (2007), Online Co-Production Services \& Consumer Preferences - A Conjoint Study: A Thesis on Co-Production Services, University of Maastricht, Faculty of Economics and Business Administration, Maastricht, November.

Etgar, M. (2008), A Descriptive Model of the Consumer Co-Production Process, Journal of the Academy of Marketing Science 36 (1), pp. 97-108.

Fitzsimmons, J. A. (1985), Consumer participation and productivity in service operations, Interfaces 15 (3), pp. 60-67.

Hume, M. (2008), Understanding core and peripheral service quality in customer repurchase of the performing arts, Managing Service Quality 18 (4), pp. 349-369.

Hume, M. et al. (2006), Understanding service experience in non-profit performing arts: implications for operations and service management, Journal of Operations Management 24, pp. 304-324.

Hume, M. et al. (2007), Exploring repurchase intention in a performing arts context: who comes? And why do they come back? International Journal of Nonprofit and Voluntary Sector Marketing, 12, pp. 135-148.

Hume, M. and G. Sullivan Mort (2010), The consequence of appraisal emotion, service quality, perceived value and customer satisfaction on repurchase intent in the performing arts, Journal of Services Marketing 24 (2), pp. 170-182.

Juarez, A., B. Schonenberg and C. Bartneck (2010), Implementing a Low-Cost CAVE System Using the CryEngine, Entertainment Computing 1 (3-4), pp. 157-164.

KEA, European Affairs (2009), The Impact of Culture on Creativity. Study prepared for the European Commission, Brussels.

Kokkinen, N. (2006), Constructing Experiences of Sacred and Eternal. Visualisations of Mircea Eliade's Archetypal Centre in Fairy Tale Illustrations, In Kylänen, M. and A. Häkkinen (eds.), Articles on Experiences 5 - Arts \& Experiences, Lapland Centre of Expertise for the Experience Industry, Rovaniemi, pp. 6-24.

Muñoz-Seca, B. (1992), Training for continuous improvement. PHD Thesis, University of Navarra, Pamplona, Spain.

Muñoz-Seca, B. (1998), Building and generating a creative and flexible workforce: Key competencies, IESE, Research Paper no. 359. 
Muñoz-Seca, B. and J. Riverola (2004), Problem Driven Management: Achieving Improvement in Operations Through Knowledge Management, Palgrave Macmillan.

Muñoz-Seca, B. and J. Riverola (2008), The New Operational Culture: The Case of the Theatre Industry, Palgrave Macmillan.

Muñoz-Seca, B. (2009), Compitiendo desde las Operaciones: la implantación de la nueva cultura operativa, IESE, Technical Note 456.

Muñoz-Seca, B. and J. Riverola (Eds.) (2010), When Business Meets Culture, Palgrave.

Muñoz-Seca, B. and M. Rodriguez (2011), Turismo y cultura, IESE, Technical Note 475.

Muñoz-Seca, B. and R. Arenas (2011), An overview of service design, IESE, Technical Note 478.

Muñoz-Seca, B. (2011). The Service Activity Sequence, IESE, Technical Note 481.

Prahalad C. K. and V. Ramaswamy (2004), Co-creation experiences: The next practice in value creation, Journal of Interactive Marketing 18 (3), pp. 5-14.

Prahalad, C. K. and V. Ramaswamy (2004), The Future of Competition: Co-Creating Unique Value with Customers, Harvard Business School Press, Boston.

Radbourne, J. (2007), The Quest for Self Actualisation - Meeting New Consumer Needs in the Cultural Industries. Paper presented to the ERSC Seminar Series "Creative Futures - Driving the Cultural Industries Marketing Agenda”, London, July 6, 2007.

Rosenstein, C. (2009), Live from Your Neighborhood: A National Study of Outdoor Arts Festivals. National Endowment for the Arts, Volume two: Seven Case Studies.

Selwood, S. (2003), Valuing Culture. Paper presented at the "Valuing Culture" conference, London, 17 June.

Siwek, S. (2009), Copyright Industries in the U.S. Economy: The 2003-2007 Report, Prepared for International Intellectual Property Alliance (IIPA).

Spohrer, J. and P. Maglio (2008), The Emergence of Service Science: Toward Systematic Service Innovations to Accelerate Co-Creation of Value, Production and Operations Management 17 (3), pp. 238-246.

Stuart, F. Ian and S. Tax (2004), Toward an Integrative Approach to Designing Service Experiences: Lessons Learned from the Theatre, Journal of Operations Management 6 (22), pp. 609-627.

Wheeler, B. (2004), The Social Construction of an Art Field: How Audience Informed the Institutionalization of Performance Art, The Journal of Arts Management, Law, and Society 33 (4), pp. 336-350.

York, P. (2003), Learning As We Go: Making Evaluation Work for Everyone, The Conservation Company.

Zomerdijk, L. and C. Voss (2011), NSD Processes and practices in experiential services, Journal of Product Innovation Management.

Zomerdijk, L. and C. Voss (2009), Service design for experience-centric services, Journal of Service Research. 